\title{
Mixed type iteration for total asymptotically nonexpansive mappings in hyperbolic spaces
}

\author{
Liang-cai Zhao', Shih-sen Chang ${ }^{2 *}$ and Jong Kyu Kim³
}

\author{
"Correspondence: \\ changss2013@aliyun.com \\ ${ }^{2}$ College of Statistics and \\ Mathematics, Yunnan University of \\ Finance and Economics, Kunming, \\ Yunnan 650221, China \\ Full list of author information is \\ available at the end of the article
}

\begin{abstract}
The purpose of this paper is to introduce the concept of total asymptotically nonexpansive mappings and to prove some $\Delta$-convergence theorems of the mixed type iteration process to approximating a common fixed point for two asymptotically nonexpansive mappings and two total asymptotically nonexpansive mappings in hyperbolic spaces. The results presented in the paper extend and improve some recent results announced in the current literature.

MSC: $47 \mathrm{H} 09 ; 47 \mathrm{H} 10$

Keywords: asymptotically nonexpansive mapping; total asymptotically nonexpansive mapping; common fixed point; hyperbolic space
\end{abstract}

\section{Introduction and preliminaries}

Most of the problems in various disciplines of science are nonlinear in nature, whereas fixed point theory proposed in the setting of normed linear spaces or Banach spaces majorly depends on the linear structure of the underlying spaces. A nonlinear framework for fixed point theory is a metric space embedded with a 'convex structure'. The class of hyperbolic spaces, nonlinear in nature, is a general abstract theoretic setting with rich geometrical structure for metric fixed point theory. The study of hyperbolic spaces has been largely motivated and dominated by questions about hyperbolic groups, one of the main objects of study in geometric group theory.

Throughout this paper, we work in the setting of hyperbolic spaces introduced by Kohlenbach [1], defined below, which is more restrictive than the hyperbolic type introduced in [2] and more general than the concept of hyperbolic space in [3].

A hyperbolic space is a metric space $(X, d)$ together with a mapping $W: X^{2} \times[0,1] \rightarrow X$ satisfying

(i) $d(u, W(x, y, \alpha)) \leq \alpha d(u, x)+(1-\alpha) d(u, y)$;

(ii) $d(W(x, y, \alpha), W(x, y, \beta))=|\alpha-\beta| d(x, y)$;

(iii) $W(x, y, \alpha)=W(y, x,(1-\alpha))$;

(iv) $d(W(x, z, \alpha), W(y, w, \alpha)) \leq(1-\alpha) d(x, y)+\alpha d(z, w)$

for all $x, y, z, w \in X$ and $\alpha, \beta \in[0,1]$. A nonempty subset $K$ of a hyperbolic space $X$ is convex if $W(x, y, \alpha) \in K$ for all $x, y \in K$ and $\alpha \in[0,1]$. The class of hyperbolic spaces contains normed spaces and convex subsets thereof, the Hilbert ball equipped with the hyperbolic metric [4], Hadamard manifolds as well as CAT(0) spaces in the sense of Gromov (see [5]).

( 2013 Zhao et al.; licensee Springer. This is an Open Access article distributed under the terms of the Creative Commons Attribution License (http://creativecommons.org/licenses/by/2.0), which permits unrestricted use, distribution, and reproduction in any medium, provided the original work is properly cited. 
A hyperbolic space is uniformly convex [6] if for any $r>0$ and $\epsilon \in(0,2]$ there exists $\delta \in(0,1]$ such that for all $u, x, y \in X$, we have

$$
d\left(W\left(x, y, \frac{1}{2}\right), u\right) \leq(1-\delta) r
$$

provided $d(x, u) \leq r, d(y, u) \leq r$ and $d(x, y) \geq \epsilon r$.

A map $\eta:(0, \infty) \times(0,2] \rightarrow(0,1]$, which provides such $\delta=\eta(r, \epsilon)$ for given $r>0$ and $\epsilon \in(0,2]$, is known as a modulus of uniform convexity of $X$. We call $\eta$ monotone if it decreases with $r$ (for fixed $\epsilon$ ), i.e., $\forall \epsilon>0, \forall r_{2} \geq r_{1}>0\left(\eta\left(r_{2}, \epsilon\right) \leq \eta\left(r_{1}, \epsilon\right)\right.$ ).

In the sequel, let $(X, d)$ be a metric space, and let $K$ be a nonempty subset of $X$. We shall denote the fixed point set of a mapping $T$ by $F(T)=\{x \in K: T x=x\}$.

A mapping $T: K \rightarrow K$ is said to be nonexpansive if

$$
d(T x, T y) \leq d(x, y), \quad \forall x, y \in K
$$

A mapping $T: K \rightarrow K$ is said to be asymptotically nonexpansive if there exists a sequence $\left\{k_{n}\right\} \subset[0, \infty)$ with $k_{n} \rightarrow 0$ such that

$$
d\left(T^{n} x, T^{n} y\right) \leq\left(1+k_{n}\right) d(x, y), \quad \forall n \geq 1, x, y \in K .
$$

A mapping $T: K \rightarrow K$ is said to be uniformly L-Lipschitzian if there exists a constant $L>0$ such that

$$
d\left(T^{n} x, T^{n} y\right) \leq L d(x, y), \quad \forall n \geq 1, x, y \in K
$$

Definition 1.1 A mapping $T: K \rightarrow K$ is said to be $\left(\left\{\mu_{n}\right\},\left\{\xi_{n}\right\}, \rho\right)$-total asymptotically nonexpansive if there exist nonnegative sequences $\left\{\mu_{n}\right\}$, $\left\{\xi_{n}\right\}$ with $\mu_{n} \rightarrow 0, \xi_{n} \rightarrow 0$ and a strictly increasing continuous function $\rho:[0, \infty) \rightarrow[0, \infty)$ with $\rho(0)=0$ such that

$$
d\left(T^{n} x, T^{n} y\right) \leq d(x, y)+\mu_{n} \rho(d(x, y))+\xi_{n}, \quad \forall n \geq 1, x, y \in K
$$

Remark 1.1 From the definitions, it is to know that each nonexpansive mapping is an asymptotically nonexpansive mapping with a sequence $\left\{k_{n}=0\right\}$, and each asymptotically nonexpansive mapping is a $\left(\left\{\mu_{n}\right\},\left\{\xi_{n}\right\}, \rho\right)$-total asymptotically nonexpansive mapping with $\xi_{n}=0$, and $\rho(t)=t, t \geq 0$.

The existence of fixed points of various nonlinear mappings has relevant applications in many branches of nonlinear analysis and topology. On the other hand, there are certain situations where it is difficult to derive conditions for the existence of fixed points for certain types of nonlinear mappings. It is worth to mention that fixed point theory for nonexpansive mappings, a limit case of a contraction mapping when the Lipschitz constant is allowed to be 1, requires tools far beyond metric fixed point theory. Iteration schemas are the only main tool for analysis of generalized nonexpansive mappings. Fixed point theory has a computational flavor as one can define effective iteration schemas for the computation of fixed points of various nonlinear mappings. The problem of finding a common 
fixed point of some nonlinear mappings acting on a nonempty convex domain often arises in applied mathematics.

The purpose of this paper is to introduce the concepts of total asymptotically nonexpansive mappings and to prove some $\Delta$-convergence theorems of the mixed type iteration process for approximating a common fixed point of two asymptotically nonexpansive mappings and two total asymptotically nonexpansive mappings in hyperbolic spaces. The results presented in the paper extend and improve some recent results given in [6-19].

In order to define the concept of $\Delta$-convergence in the general setup of hyperbolic spaces, we first collect some basic concepts.

Let $\left\{x_{n}\right\}$ be a bounded sequence in a hyperbolic space $X$. For $x \in X$, we define a continuous functional $r\left(\cdot,\left\{x_{n}\right\}\right): X \rightarrow[0, \infty)$ by

$$
r\left(x,\left\{x_{n}\right\}\right)=\limsup _{n \rightarrow \infty} d\left(x, x_{n}\right)
$$

The asymptotic radius $r\left(\left\{x_{n}\right\}\right)$ of $\left\{x_{n}\right\}$ is given by

$$
r\left(\left\{x_{n}\right\}\right)=\inf \left\{r\left(x,\left\{x_{n}\right\}\right): x \in X\right\} .
$$

The asymptotic center $A_{k}\left(\left\{x_{n}\right\}\right)$ of a bounded sequence $\left\{x_{n}\right\}$ with respect to $K \subset X$ is the set

$$
A_{K}\left(\left\{x_{n}\right\}\right)=\left\{x \in X: r\left(x,\left\{x_{n}\right\}\right) \leq r\left(y,\left\{x_{n}\right\}\right), \forall y \in K\right\} .
$$

This is the set of minimizers of the functional $r\left(\cdot,\left\{x_{n}\right\}\right)$. If the asymptotic center is taken with respect to $X$, then it is simply denoted by $A\left(\left\{x_{n}\right\}\right)$. It is known that uniformly convex Banach spaces and CAT $(0)$ spaces enjoy the property that 'bounded sequences have unique asymptotic centers with respect to closed convex subsets'. The following lemma is due to Leustean [20] and ensures that this property also holds in a complete uniformly convex hyperbolic space.

Lemma 1.1 [20] Let $(X, d, W)$ be a complete uniformly convex hyperbolic space with monotone modulus of uniform convexity. Then every bounded sequence $\left\{x_{n}\right\}$ in $X$ has a unique asymptotic center with respect to any nonempty closed convex subset $K$ of $X$.

Recall that a sequence $\left\{x_{n}\right\}$ in $X$ is said to $\Delta$-converge to $x \in X$ if $x$ is the unique asymptotic center of $\left\{u_{n}\right\}$ for every subsequence $\left\{u_{n}\right\}$ of $\left\{x_{n}\right\}$. In this case, we write $\Delta-\lim _{n \rightarrow \infty} x_{n}=$ $x$ and call $x$ the $\Delta$-limit of $\left\{x_{n}\right\}$.

A mapping $T: K \rightarrow K$ is semi-compact if every bounded sequence $\left\{x_{n}\right\} \subset K$ satisfying $d\left(x_{n}, T x_{n}\right) \rightarrow 0$ has a convergent subsequence.

Lemma 1.2 [9] Let $\left\{a_{n}\right\},\left\{b_{n}\right\}$ and $\left\{\delta_{n}\right\}$ be sequences of nonnegative real numbers satisfying

$$
a_{n+1} \leq\left(1+\delta_{n}\right) a_{n}+b_{n}, \quad \forall n \geq 1
$$

If $\sum_{n=1}^{\infty} \delta_{n}<\infty$ and $\sum_{n=1}^{\infty} b_{n}<\infty$, then the limit $\lim _{n \rightarrow \infty} a_{n}$ exists. If there exists a subsequence $\left\{a_{n_{i}}\right\} \subset\left\{a_{n}\right\}$ such that $a_{n_{i}} \rightarrow 0$, then $\lim _{n \rightarrow \infty} a_{n}=0$. 
Lemma 1.3 [12] Let $(X, d, W)$ be a uniformly convex hyperbolic space with monotone modulus of uniform convexity $\eta$. Let $x \in X$ and $\left\{\alpha_{n}\right\}$ be a sequence in $[a, b]$ for some $a, b \in(0,1)$. If $\left\{x_{n}\right\}$ and $\left\{y_{n}\right\}$ are sequences in $X$ such that

$$
\begin{aligned}
& \limsup _{n \rightarrow \infty} d\left(x_{n}, x\right) \leq c, \quad \limsup _{n \rightarrow \infty} d\left(y_{n}, x\right) \leq c, \\
& \lim _{n \rightarrow \infty} d\left(W\left(x_{n}, y_{n}, \alpha_{n}\right), x\right)=c,
\end{aligned}
$$

for some $c \geq 0$, then $\lim _{n \rightarrow \infty} d\left(x_{n}, y_{n}\right)=0$.

Lemma 1.4 [12] Let $K$ be a nonempty closed convex subset of uniformly convex hyperbolic space and $\left\{x_{n}\right\}$ be a bounded sequence in $K$ such that $A\left(\left\{x_{n}\right\}\right)=\{y\}$ and $r\left(\left\{x_{n}\right\}\right)=\zeta$. If $\left\{y_{m}\right\}$ is another sequence in $K$ such that $\lim _{m \rightarrow \infty} r\left(y_{m},\left\{x_{n}\right\}\right)=\zeta$, then $\lim _{m \rightarrow \infty} y_{m}=y$.

\section{Main results}

Theorem 2.1 Let $K$ be a nonempty closed convex subset of a complete uniformly convex hyperbolic space $X$ with monotone modulus of uniform convexity $\eta$. Let $T_{i}: K \rightarrow K, i=1,2$, be a uniformly $L_{i}$-Lipschitzian and $\left(\left\{\mu_{n}^{i}\right\},\left\{\xi_{n}^{i}\right\}, \rho^{i}\right)$-total asymptotically nonexpansive mapping with sequence $\left\{\mu_{n}^{i}\right\}$ and $\left\{\xi_{n}^{i}\right\}$ satisfying $\lim _{n \rightarrow \infty} \mu_{n}^{i}=0, \lim _{n \rightarrow \infty} \xi_{n}^{i}=0$ and a strictly increasing function $\rho^{i}:[0, \infty) \rightarrow[0, \infty)$ with $\rho^{i}(0)=0, i=1,2$, let $S_{i}: K \rightarrow K, i=1,2$, be a uniformly $\tilde{L}_{i}$-Lipschitzian and asymptotically nonexpansive mapping with sequence $\left\{k_{n}^{i}\right\}$ satisfying $\lim _{n \rightarrow \infty} k_{n}^{i}=0$. Assume that $\mathcal{F}:=\bigcap_{i=1}^{2} F\left(T_{i}\right) \cap F\left(S_{i}\right) \neq \emptyset$, and for arbitrarily chosen $x_{1} \in K,\left\{x_{n}\right\}$ is defined as follows:

$$
\left\{\begin{array}{l}
x_{n+1}=W\left(S_{1}^{n} x_{n}, T_{1}^{n} y_{n}, \alpha_{n}\right), \\
y_{n}=W\left(S_{2}^{n} x_{n}, T_{2}^{n} x_{n}, \beta_{n}\right),
\end{array}\right.
$$

where $\left\{\mu_{n}^{i}\right\},\left\{\xi_{n}^{i}\right\}, \rho^{i}, k_{n}^{i}, i=1,2,\left\{\alpha_{n}\right\}$ and $\left\{\beta_{n}\right\}$ satisfy the following conditions:

(1) $\sum_{n=1}^{\infty} \mu_{n}^{i}<\infty, \sum_{n=1}^{\infty} \xi_{n}^{i}<\infty, \sum_{n=1}^{\infty} k_{n}^{i}<\infty, i=1,2$;

(2) There exist constants $a, b \in(0,1)$ with $0<b(1-a) \leq \frac{1}{2}$ such that $\left\{\alpha_{n}\right\} \subset[a, b]$ and $\left\{\beta_{n}\right\} \subset[a, b]$

(3) There exists a constant $M^{*}>0$ such that $\rho^{i}(r) \leq M^{*} r, r>0, i=1,2$;

(4) $d\left(x, T_{i} y\right) \leq d\left(S_{i} x, T_{i} y\right)$ for all $x, y \in K$ and $i=1,2$.

Then the sequence $\left\{x_{n}\right\}$ defined by (2.1) $\Delta$-converges to a common fixed point of $\mathcal{F}:=$ $\bigcap_{i=1}^{2} F\left(T_{i}\right) \cap F\left(S_{i}\right)$.

Proof Set $L=\max \left\{L_{i}, \tilde{L}_{i}, i=1,2\right\}, \mu_{n}=\max \left\{\mu_{n}^{i}, k_{n}^{i}, i=1,2\right\}$ and $\xi_{n}=\max \left\{\xi_{n}^{i}, i=1,2\right\}, \rho=$ $\max \left\{\rho^{i}, i=1,2\right\}$. By condition (1), we know that $\sum_{n=1}^{\infty} \mu_{n}<\infty, \sum_{n=1}^{\infty} \xi_{n}<\infty$. The proof of Theorem 2.1 is divided into four steps.

Step 1. First we prove that $\lim _{n \rightarrow \infty} d\left(x_{n}, p\right)$ exists for each $p \in \mathcal{F}$.

For any given $p \in \mathcal{F}$, since $T_{i}, i=1,2$, is a total asymptotically nonexpansive mapping and $S_{i}, i=1,2$, is an asymptotically nonexpansive mapping, by condition (3) and (2.1), we have

$$
\begin{aligned}
d\left(x_{n+1}, p\right) & =d\left(W\left(S_{1}^{n} x_{n}, T_{1}^{n} y_{n}, \alpha_{n}\right), p\right) \\
& \leq\left(1-\alpha_{n}\right) d\left(S_{1}^{n} x_{n}, p\right)+\alpha_{n} d\left(T_{1}^{n} y_{n}, p\right)
\end{aligned}
$$




$$
\begin{aligned}
\leq & \left(1-\alpha_{n}\right)\left[\left(1+\mu_{n}\right) d\left(x_{n}, p\right)\right] \\
& +\alpha_{n}\left[d\left(y_{n}, p\right)+\mu_{n} \rho\left(d\left(y_{n}, p\right)\right)+\xi_{n}\right] \\
\leq & \left(1-\alpha_{n}\right)\left[\left(1+\mu_{n}\right) d\left(x_{n}, p\right)\right]+\alpha_{n}\left[\left(1+\mu_{n} M^{*}\right) d\left(y_{n}, p\right)+\xi_{n}\right],
\end{aligned}
$$

where

$$
\begin{aligned}
d\left(y_{n}, p\right)= & d\left(W\left(S_{2}^{n} x_{n}, T_{2}^{n} x_{n}, \beta_{n}\right), p\right) \\
\leq & \left(1-\beta_{n}\right) d\left(S_{2}^{n} x_{n}, p\right)+\beta_{n} d\left(T_{2}^{n} x_{n}, p\right) \\
\leq & \left(1-\beta_{n}\right)\left[\left(1+\mu_{n}\right) d\left(x_{n}, p\right)\right] \\
& +\beta_{n}\left[d\left(x_{n}, p\right)+\mu_{n} \rho\left(d\left(x_{n}, p\right)\right)+\xi_{n}\right] \\
\leq & \left(1-\beta_{n}\right)\left[\left(1+\mu_{n}\right) d\left(x_{n}, p\right)\right]+\beta_{n}\left[\left(1+\mu_{n} M^{*}\right) d\left(x_{n}, p\right)+\xi_{n}\right] \\
= & {\left[1+\left(1-\beta_{n}\right) \mu_{n}+\beta_{n} \mu_{n} M^{*}\right] d\left(x_{n}, p\right)+\beta_{n} \xi_{n} } \\
\leq & \left(1+\mu_{n}+\beta_{n} \mu_{n} M^{*}\right) d\left(x_{n}, p\right)+\beta_{n} \xi_{n} .
\end{aligned}
$$

Substituting (2.3) into (2.2) and simplifying it, we have

$$
\begin{aligned}
d\left(x_{n+1}, p\right) \leq & \left(1-\alpha_{n}\right)\left[\left(1+\mu_{n}\right) d\left(x_{n}, p\right)\right] \\
& +\alpha_{n}\left[\left(1+\mu_{n} M^{*}\right)\left(\left(1+\mu_{n}+\beta_{n} \mu_{n} M^{*}\right) d\left(x_{n}, p\right)+\beta_{n} \xi_{n}\right)+\xi_{n}\right] \\
= & \left\{1+\left[1+\alpha_{n} M^{*}\left(1+\beta_{n}+\mu_{n}+\beta_{n} \mu_{n} M^{*}\right)\right] \mu_{n}\right\} d\left(x_{n}, p\right) \\
& +\left(1+\beta_{n}+\beta_{n} \mu_{n} M^{*}\right) \alpha_{n} \xi_{n} \\
= & \left(1+\delta_{n}\right) d\left(x_{n}, p\right)+b_{n},
\end{aligned}
$$

where $\delta_{n}=\mu_{n}\left(1+\alpha_{n} M^{*}\left(1+\beta_{n}+\mu_{n}+\beta_{n} \mu_{n} M^{*}\right)\right), b_{n}=\left(1+\beta_{n}+\beta_{n} \mu_{n} M^{*}\right) \alpha_{n} \xi_{n}$. Since $\sum_{n=1}^{\infty} \mu_{n}<\infty, \sum_{n=1}^{\infty} \xi_{n}<\infty$ and condition (2), it follows from Lemma 1.2 that $\lim _{n \rightarrow \infty} d\left(x_{n}, p\right)$ exists for $p \in \mathcal{F}$.

Step 2. We show that

$$
\lim _{n \rightarrow \infty} d\left(x_{n}, T_{i} x_{n}\right)=0, \quad \lim _{n \rightarrow \infty} d\left(x_{n}, S_{i} x_{n}\right)=0, \quad i=1,2 .
$$

For each $p \in \mathcal{F}$, from the proof of Step 1, we know that $\lim _{n \rightarrow \infty} d\left(x_{n}, p\right)$ exists. We may assume that $\lim _{n \rightarrow \infty} d\left(x_{n}, p\right)=c \geq 0$. If $c=0$, then the conclusion is trivial. Next, we deal with the case $c>0$. From (2.3), we have

$$
d\left(y_{n}, p\right) \leq\left(1+\mu_{n}+\beta_{n} \mu_{n} M^{*}\right) d\left(x_{n}, p\right)+\beta_{n} \xi_{n} .
$$

Taking lim sup on both sides in (2.6), we have

$$
\limsup _{n \rightarrow \infty} d\left(y_{n}, p\right) \leq c
$$

In addition, since

$$
d\left(T_{1}^{n} y_{n}, p\right) \leq d\left(y_{n}, p\right)+\mu_{n} \rho\left(d\left(y_{n}, p\right)\right)+\xi_{n} \leq\left(1+\mu_{n} M^{*}\right) d\left(y_{n}, p\right)+\xi_{n},
$$


and

$$
d\left(S_{1}^{n} x_{n}, p\right) \leq\left(1+\mu_{n}\right) d\left(x_{n}, p\right),
$$

then we have

$$
\limsup _{n \rightarrow \infty} d\left(T_{1}^{n} y_{n}, p\right) \leq c
$$

and

$$
\limsup _{n \rightarrow \infty} d\left(S_{1}^{n} x_{n}, p\right) \leq c .
$$

Since $\lim _{n \rightarrow \infty} d\left(x_{n+1}, p\right)=c$, it is easy to prove that

$$
\lim _{n \rightarrow \infty} d\left(W\left(S_{1}^{n} x_{n}, T_{1}^{n} y_{n}, \alpha_{n}\right), p\right)=c .
$$

It follows from (2.8)-(2.10) and Lemma 1.3 that

$$
\lim _{n \rightarrow \infty} d\left(S_{1}^{n} x_{n}, T_{1}^{n} y_{n}\right)=0 .
$$

By the same method, we can also prove that

$$
\lim _{n \rightarrow \infty} d\left(S_{2}^{n} x_{n}, T_{2}^{n} x_{n}\right)=0 .
$$

By virtue of condition (4), it follows from (2.11) and (2.12) that

$$
\lim _{n \rightarrow \infty} d\left(x_{n}, T_{1}^{n} y_{n}\right) \leq \lim _{n \rightarrow \infty} d\left(S_{1}^{n} x_{n}, T_{1}^{n} y_{n}\right)=0
$$

and

$$
\lim _{n \rightarrow \infty} d\left(x_{n}, T_{2}^{n} x_{n}\right) \leq \lim _{n \rightarrow \infty} d\left(S_{2}^{n} x_{n}, T_{2}^{n} x_{n}\right)=0 .
$$

From (2.1) and (2.12) we have

$$
\begin{aligned}
d\left(y_{n}, S_{2}^{n} x_{n}\right) & =d\left(W\left(S_{2}^{n} x_{n}, T_{2}^{n} x_{n}, \beta_{n}\right), S_{2}^{n} x_{n}\right) \\
& \leq \beta_{n} d\left(T_{2}^{n} x_{n}, S_{2}^{n} x_{n}\right) \rightarrow 0 \quad(\text { as } n \rightarrow \infty) .
\end{aligned}
$$

Observe that

$$
d\left(x_{n}, y_{n}\right)=d\left(x_{n}, T_{2}^{n} x_{n}\right)+d\left(T_{2}^{n} x_{n}, S_{2}^{n} x_{n}\right)+d\left(S_{2}^{n} x_{n}, y_{n}\right) .
$$

It follows from (2.14) and (2.15) that

$$
\lim _{n \rightarrow \infty} d\left(x_{n}, y_{n}\right)=0
$$


This together with (2.13) implies that

$$
\begin{aligned}
d\left(x_{n}, T_{1}^{n} x_{n}\right) & \leq d\left(x_{n}, T_{1}^{n} y_{n}\right)+d\left(T_{1}^{n} y_{n}, T_{1}^{n} x_{n}\right) \\
& \leq d\left(x_{n}, T_{1}^{n} y_{n}\right)+L d\left(y_{n}, x_{n}\right) \rightarrow 0 \quad(n \rightarrow \infty) .
\end{aligned}
$$

On the other hand, from (2.11) and (2.16), we have

$$
\begin{aligned}
d\left(S_{1}^{n} x_{n}, T_{1}^{n} x_{n}\right) & \leq d\left(S_{1}^{n} x_{n}, T_{1}^{n} y_{n}\right)+d\left(T_{1}^{n} y_{n}, T_{1}^{n} x_{n}\right) \\
& \leq d\left(S_{1}^{n} x_{n}, T_{1}^{n} y_{n}\right)+L d\left(y_{n}, x_{n}\right) \rightarrow 0 \quad(n \rightarrow \infty) .
\end{aligned}
$$

Hence from (2.17) and (2.18), we have that

$$
d\left(S_{1}^{n} x_{n}, x_{n}\right) \leq d\left(S_{1}^{n} x_{n}, T_{1}^{n} x_{n}\right)+d\left(T_{1}^{n} x_{n}, x_{n}\right) \rightarrow 0 \quad(n \rightarrow \infty) .
$$

In addition, since

$$
\begin{aligned}
d\left(x_{n+1}, x_{n}\right) & =d\left(W\left(S_{1}^{n} x_{n}, T_{1}^{n} y_{n}, \alpha_{n}\right), x_{n}\right) \\
& \leq\left(1-\alpha_{n}\right) d\left(S_{1}^{n} x_{n}, x_{n}\right)+\alpha_{n} d\left(T_{1}^{n} y_{n}, x_{n}\right),
\end{aligned}
$$

from (2.13) and (2.19), we have

$$
\lim _{n \rightarrow \infty} d\left(x_{n+1}, x_{n}\right)=0
$$

Finally, for all $i=1,2$, we have

$$
\begin{aligned}
d\left(x_{n}, T_{i} x_{n}\right) \leq & d\left(x_{n}, x_{n+1}\right)+d\left(x_{n+1}, T_{i}^{n+1} x_{n+1}\right) \\
& +d\left(T_{i}^{n+1} x_{n+1}, T_{i}^{n+1} x_{n}\right)+d\left(T_{i}^{n+1} x_{n}, T_{i} x_{n}\right) \\
\leq & (1+L) d\left(x_{n}, x_{n+1}\right)+d\left(x_{n+1}, T_{i}^{n+1} x_{n+1}\right)+L d\left(T_{i}^{n} x_{n}, x_{n}\right) .
\end{aligned}
$$

It follows from (2.14), (2.17) and (2.20) that

$$
\lim _{n \rightarrow \infty} d\left(x_{n}, T_{i} x_{n}\right)=0, \quad i=1,2 .
$$

By virtue of condition (4), $d\left(S_{i} x_{n}, T_{i}^{n} x_{n}\right) \leq d\left(S_{i}^{n} x_{n}, T_{i}^{n} x_{n}\right)$, we have

$$
\begin{aligned}
d\left(x_{n}, S_{i} x_{n}\right) & \leq d\left(x_{n}, T_{i}^{n} x_{n}\right)+d\left(S_{i} x_{n}, T_{i}^{n} x_{n}\right) \\
& \leq d\left(x_{n}, T_{i}^{n} x_{n}\right)+d\left(S_{i}^{n} x_{n}, T_{i}^{n} x_{n}\right),
\end{aligned}
$$

it follows from (2.12), (2.14), (2.17) and (2.18) that

$$
\lim _{n \rightarrow \infty} d\left(x_{n}, S_{i} x_{n}\right)=0, \quad i=1,2 .
$$

Step 3. Now we prove that the sequence $\left\{x_{n}\right\} \Delta$-converges to a common fixed point of $\mathcal{F}:=\bigcap_{i=1}^{2} F\left(T_{i}\right) \cap F\left(S_{i}\right)$. 
In fact, for each $p \in F, \lim _{n \rightarrow \infty} d\left(x_{n}, p\right)$ exists. This implies that the sequence $\left\{d\left(x_{n}, p\right)\right\}$ is bounded, so is the sequence $\left\{x_{n}\right\}$. Hence, by virtue of Lemma 1.1, $\left\{x_{n}\right\}$ has a unique asymptotic center $A_{K}\left(\left\{x_{n}\right\}\right)=\{x\}$.

Let $\left\{u_{n}\right\}$ be any subsequence of $\left\{x_{n}\right\}$ with $A_{K}\left(\left\{u_{n}\right\}\right)=\{u\}$. It follows from (2.5) that

$$
\lim _{n \rightarrow \infty} d\left(u_{n}, T_{i} u_{n}\right)=0
$$

Now, we show that $u \in F\left(T_{i}\right)$. For this, we define a sequence $\left\{z_{n}\right\}$ in $K$ by $z_{j}=T_{i}^{j} u$. So we calculate

$$
\begin{aligned}
d\left(z_{j}, u_{n}\right) & \leq d\left(T_{i}^{j} u, T_{i}^{j} u_{n}\right)+d\left(T_{i}^{j} u_{n}, T_{i}^{j-1} u_{n}\right)+\cdots+d\left(T_{i} u_{n}, u_{n}\right) \\
& \leq d\left(u, u_{n}\right)+\mu_{j} \rho\left(d\left(u, u_{n}\right)\right)+\xi_{j}+\sum_{k=1}^{j} d\left(T_{i}^{k} u_{n}, T_{i}^{k-1} u_{n}\right) \\
& \leq\left(1+\mu_{j} M^{*}\right) d\left(u, u_{n}\right)+\xi_{j}+\sum_{k=1}^{j} d\left(T_{i}^{k} u_{n}, T_{i}^{k-1} u_{n}\right) .
\end{aligned}
$$

Since $T_{i}$ is uniformly $L$-Lipschitzian, from (2.22) we have

$$
d\left(z_{j}, u_{n}\right) \leq\left(1+\mu_{j} M^{*}\right) d\left(u, u_{n}\right)+\xi_{j}+j L d\left(T_{i} u_{n}, u_{n}\right)
$$

Taking lim sup on both sides of the above estimate and using (2.21), we have

$$
\begin{aligned}
r\left(z_{j},\left\{u_{n}\right\}\right) & =\limsup _{n \rightarrow \infty} d\left(z_{j}, u_{n}\right) \\
& \leq\left(1+\mu_{j} M^{*}\right) \limsup _{n \rightarrow \infty} d\left(u, u_{n}\right)+\xi_{j} \\
& =\left(1+\mu_{j} M^{*}\right) r\left(u,\left\{u_{n}\right\}\right)+\xi_{j} .
\end{aligned}
$$

And so

$$
\limsup _{j \rightarrow \infty} r\left(z_{j},\left\{u_{n}\right\}\right) \leq r\left(u,\left\{u_{n}\right\}\right)
$$

Since $A_{K}\left(\left\{u_{n}\right\}\right)=\{u\}$, by the definition of asymptotic center $A_{K}\left(\left\{u_{n}\right\}\right)$ of a bounded sequence $\left\{u_{n}\right\}$ with respect to $K \subset X$, we have

$$
r\left(u,\left\{u_{n}\right\}\right) \leq r\left(y,\left\{u_{n}\right\}\right), \quad \forall y \in K
$$

This implies that

$$
\liminf _{j \rightarrow \infty} r\left(z_{j},\left\{u_{n}\right\}\right) \geq r\left(u,\left\{u_{n}\right\}\right)
$$

Therefore we have

$$
\lim _{j \rightarrow \infty} r\left(z_{j},\left\{u_{n}\right\}\right)=r\left(u,\left\{u_{n}\right\}\right) .
$$


It follows from Lemma 1.4 that $\lim _{j \rightarrow \infty} T_{i}^{j} u=u$. As $T_{i}$ is uniformly continuous, so that $T_{i} u=T_{i}\left(\lim _{j \rightarrow \infty} T_{i}^{j} u\right)=\lim _{j \rightarrow \infty} T_{i}^{j+1} u=u$. That is, $u \in F\left(T_{i}\right)$. Similarly, we also can show that $u \in F\left(S_{i}\right)$. Hence, $u$ is the common fixed point of $T_{i}$ and $S_{i}$. Reasoning as above by utilizing the uniqueness of asymptotic centers, we get that $x=u$. Since $\left\{u_{n}\right\}$ is an arbitrary subsequence of $\left\{x_{n}\right\}$, therefore $A\left(\left\{u_{n}\right\}\right)=\{u\}$ for all subsequence $\left\{u_{n}\right\}$ of $\left\{x_{n}\right\}$. This proves that $\left\{x_{n}\right\} \Delta$-converges to a common fixed point of $\mathcal{F}:=\bigcap_{i=1}^{2} F\left(T_{i}\right) \cap F\left(S_{i}\right)$. This completes the proof.

The following theorem can be obtained from Theorem 2.1 immediately.

Theorem 2.2 Let $K$ be a nonempty closed convex subset of a complete uniformly convex hyperbolic space $X$ with monotone modulus of uniform convexity $\eta$. Let $T_{i}: K \rightarrow K, i=1,2$, be a uniformly $L_{i}$-Lipschitzian and asymptotically nonexpansive mapping with sequence $\left\{t_{n}^{i}\right\} \subset[1, \infty)$ satisfying $\lim _{n \rightarrow \infty} t_{n}^{i}=1$, and $S_{i}: K \rightarrow K, i=1,2$, be a nonexpansive mapping. Assume that $\mathcal{F}:=\bigcap_{i=1}^{2} F\left(T_{i}\right) \cap F\left(S_{i}\right)$, for arbitrarily chosen $x_{1} \in K,\left\{x_{n}\right\}$ is defined as follows:

$$
\left\{\begin{array}{l}
x_{n+1}=W\left(S_{1} x_{n}, T_{1}^{n} y_{n}, \alpha_{n}\right), \\
y_{n}=W\left(S_{2} x_{n}, T_{2}^{n} x_{n}, \beta_{n}\right),
\end{array}\right.
$$

where $\left\{t_{n}^{i}\right\}, i=1,2,\left\{\alpha_{n}\right\}$ and $\beta_{n}$ satisfy the following conditions:

(1) $\sum_{n=1}^{\infty}\left(t_{n}^{i}-1\right)<\infty, i=1,2$;

(2) There exist constants $a, b \in(0,1)$ with $0<b(1-a) \leq \frac{1}{2}$ such that $\left\{\alpha_{n}\right\} \subset[a, b]$ and $\left\{\beta_{n}\right\} \subset[a, b]$

(3) $d\left(x, T_{i} y\right) \leq d\left(S_{i} x, T_{i} y\right)$ for all $x, y \in K$ and $i=1,2$.

Then the sequence $\left\{x_{n}\right\}$ defined in (2.23) $\Delta$-converges to a common fixed point of $\mathcal{F}:=$ $\bigcap_{i=1}^{2} F\left(T_{i}\right) \cap F\left(S_{i}\right)$.

Proof Take $\rho^{i}(t)=t, t \geq 0, \xi_{n}^{i}=0, \mu_{n}^{i}=t_{n}^{i}-1, k_{n}^{i}=0, i=1,2$, in Theorem 2.1. Since all the conditions in Theorem 2.1 are satisfied, it follows from Theorem 2.1 that the sequence $\left\{x_{n}\right\} \Delta$-converges to a common fixed point of $\mathcal{F}:=\bigcap_{i=1}^{2} F\left(T_{i}\right) \cap F\left(S_{i}\right)$.

This completes the proof of Theorem 2.2.

Theorem 2.3 Let $K$ be a nonempty closed convex subset of a complete uniformly convex hyperbolic space $X$ with monotone modulus of uniform convexity $\eta$. Let $T_{i}: K \rightarrow K, i=1,2$, be a uniformly $L_{i}$-Lipschitzian and asymptotically nonexpansive mapping with sequence $\left\{t_{n}^{i}\right\} \subset[1, \infty)$ satisfying $\lim _{n \rightarrow \infty} t_{n}^{i}=1$. Assume that $\mathcal{F}:=\bigcap_{i=1}^{2} F\left(T_{i}\right)$, for arbitrarily chosen $x_{1} \in K,\left\{x_{n}\right\}$ is defined as follows:

$$
\left\{\begin{array}{l}
x_{n+1}=W\left(x_{n}, T_{1}^{n} y_{n}, \alpha_{n}\right), \\
y_{n}=W\left(x_{n}, T_{2}^{n} x_{n}, \beta_{n}\right),
\end{array}\right.
$$

where $\left\{t_{n}^{i}\right\}, i=1,2,\left\{\alpha_{n}\right\}$ and $\beta_{n}$ satisfy the following conditions:

(1) $\sum_{n=1}^{\infty}\left(t_{n}^{i}-1\right)<\infty, i=1,2$;

(2) There exist constants $a, b \in(0,1)$ with $0<b(1-a) \leq \frac{1}{2}$ such that $\left\{\alpha_{n}\right\} \subset[a, b]$ and $\left\{\beta_{n}\right\} \subset[a, b]$. 
Then the sequence $\left\{x_{n}\right\}$ defined in (2.24) $\Delta$-converges to a common fixed point of $\mathcal{F}:=$ $\bigcap_{i=1}^{2} F\left(T_{i}\right)$.

Proof Take $\rho^{i}(t)=t, t \geq 0, \xi_{n}^{i}=0, \mu_{n}^{i}=t_{n}^{i}-1, S_{i}=I, i=1,2$, in Theorem 2.1. Since all the conditions in Theorem 2.1 are satisfied, it follows from Theorem 2.1 that the sequence $\left\{x_{n}\right\}$ $\Delta$-converges to a common fixed point of $\mathcal{F}:=\bigcap_{i=1}^{2} F\left(T_{i}\right)$.

This completes the proof of Theorem 2.3.

\section{Competing interests}

The authors declare that they have no competing interests.

\section{Authors' contributions}

All authors contributed equally and significantly to this research work. All authors read and approved the final manuscript.

\section{Author details}

${ }^{1}$ Institute of Mathematics, Yibin University, Yibin, Sichuan 644000, China. ${ }^{2}$ College of Statistics and Mathematics, Yunnan University of Finance and Economics, Kunming, Yunnan 650221, China. ${ }^{3}$ Department of Mathematics Education, Kyungnam University, Changwon, Gyeongnam 631-701, Korea.

\section{Acknowledgements}

The authors would like to express their thanks to the editors and referees for their useful comments and suggestions. This work is supported by Scientific Research Fund of SiChuan Provincial Education Department (No. 11ZA222) and the Natural Science Foundation of Yibin University (No. 2012S07) and the National Natural Science foundation of China (Grant No. 11361070)

Received: 24 July 2013 Accepted: 3 December 2013 Published: 31 Dec 2013

\section{References}

1. Kohlenbach, U: Some logical metatheorems with applications in functional analysis. Trans. Amer. Math. Soc. 357(1), 89-128 (2004)

2. Kuhfittig, PKF: Common fixed points of nonexpansive mappings by iteration. Pacific J. Math. 97(1), 137-139 (1981)

3. Reich, S, Shafrir, I: Nonexpansive iterations in hyperbolic spaces. Nonlinear Anal. 15, 537-558 (1990)

4. Goebel, K, Reich, S: Uniform Convexity, Hyperbolic Geometry and Nonexpansive Mappings. Dekker, New York (1984)

5. Bridson, N, Haefliger, A: Metric Spaces of Non-Positive Curvature. Springer, Berlin (1999)

6. Leustean, L: A quadratic rate of asymptotic regularity for CAT(0) spaces. J. Math. Anal. Appl. 325, 386-399 (2007)

7. Agarwal, RP, O'Regan, D, Sahu, DR: Iterative construction of fixed points of nearly asymptotically nonexpansive mappings. J. Nonlinear convex Anal. 8(1), 61-79 (2007)

8. Chang, SS, Cho, YJ, Zhou, H: Demiclosed principal and weak convergence problms for asymptotically nonexpansive mappings. J. Korean. Math. Soc. 38(6), 1245-1260 (2001)

9. Chang, SS, Wang, L, Lee, HWJ, et al.: Total asymptotically nonexpansive mappings in a CAT(0) space demiclosed principle and $\Delta$-convergence theorems for total asymptotically nonexpansive mappings in a CAT(0) space. Appl. Math. Comput 219, 2611-2617 (2012)

10. Fukhar-ud-din, H, Khan, AR: Approximating common fixed points of asymptotically nonexpansive maps in uniformly convex Banach spaces. Comput. Math. Appl. 53, 1349-1360 (2007)

11. Gu, F, Fu, Q: Strong convergence theorems for common fixed points of multistep iterations with errors in Banach spaces. J. Inequal. Appl. 2009, Article ID 819036 (2009). doi:10.1155/2009/819036

12. Khan, AR, Fukhar-ud-din, H, Kuan, MAA: An implicit algorithm for two finite families of nonexpansive maps in hyperbolic spaces. Fixed Point Theory Appl. 2012, Article ID 54 (2012). doi:10.1186/1687-1812-2012-54

13. Khan, AR, Khamsi, MA, Fukhar-ud-din, H: Strong convergence of a general iteration scheme in CAT(0) spaces. Nonlinear Anal. 74, 783-791 (2011)

14. Osilike, MO, Aniagbosor, SC: Weak and strong convergence theorems for fixed points of asymptotically nonexpansive mappings. Math. Compt. Model. 32, 1181-1191 (2000)

15. Sahin, A, Basarir, M: On the strong convergence of a modified S-iteration process for asymptotically quasi-nonexpansive mappings in a CAT(0) space. Fixed Point Theory Appl. 2013, Article ID 12 (2013). doi:10.1186/1687-1812-2013-12

16. Schu, J: Weak and strong convergence to fixed points of asymptotically nonexpansive mappings. Bull. Aust. Math Soc. 43, 153-159 (1991)

17. Schu, J: Iterative construction of fixed points of asymptotically nonexpansive mappings. J. Math. Anal. Appl. 158, 407-413 (1991)

18. Tan, KK, Xu, HK: Fixed point iteration process for asymptotically nonexpansive mappings. Proc. Amer. Math. Soc. 122(3), 733-739 (1994)

19. Yao, Y, Liou, YC: New iterative schemes for asymptotically quasi-nonexpansive mappings. J. Inequal. Appl. 2010, Article ID 934692 (2010). doi:10.1155/2010/934692

20. Leustean, L: Nonexpansive iteration in uniformly convex W-hyperbolic spaces. In: Leizarowitz, A, Mordukhovich, BS, Shafrir, I, Zaslavski, A (eds.) Nonlinear Analysis and Optimization I: Nonlinear Analysis. Contemporary Mathematics, vol. 513, pp. 193-209. Am. Math. Soc., Providence (2010) 
10.1186/1687-1812-2013-353

Cite this article as: Zhao et al.: Mixed type iteration for total asymptotically nonexpansive mappings in hyperbolic spaces. Fixed Point Theory and Applications 2013, 2013:353

Submit your manuscript to a SpringerOpen ${ }^{\circ}$ journal and benefit from:

- Convenient online submission

- Rigorous peer review

- Immediate publication on acceptance

Open access: articles freely available online

- High visibility within the field

- Retaining the copyright to your article

Submit your next manuscript at $\boldsymbol{s p r i n g e r o p e n . c o m ~}$ 